Article

\title{
Uncertainties in CERES Top-of-Atmosphere Fluxes Caused by Changes in Accompanying Imager
}

\author{
Wenying Su ${ }^{1, *}$, Lusheng Liang ${ }^{2}$, Hailan Wang ${ }^{3}$ and Zachary A. Eitzen ${ }^{2}$ \\ 1 Science Directorate, NASA Langley Research Center, Mail Stop 420, Hampton, VA 23681, USA \\ 2 Science Systems \& Applications, Inc., 1 Enterprise Pkwy \#200, Hampton, VA 23666, USA; \\ lusheng.liang@nasa.gov (L.L.); zachary.a.eitzen@nasa.gov (Z.A.E.) \\ 3 Climate Prediction Center, National Centers for Environmental Prediction, NOAA, \\ 5830 University Research Court, College Park, MD 20740, USA; hailan.wang@noaa.gov \\ * Correspondence: Wenying.Su-1@nasa.gov
}

Received: 18 May 2020; Accepted: 22 June 2020; Published: 25 June 2020

check for updates

\begin{abstract}
The Clouds and the Earth's Radiant Energy System (CERES) project provides observations of Earth's radiation budget using measurements from CERES instruments on board the Terra, Aqua, Suomi National Polar-orbiting Partnership (S-NPP), and NOAA-20 satellites. The CERES top-of-atmosphere (TOA) fluxes are produced by converting radiance measurements using empirical angular distribution models, which are functions of cloud properties that are retrieved from imagers flying with the CERES instruments. As the objective is to create a long-term climate data record, not only calibration consistency of the six CERES instruments needs to be maintained for the entire time period, it is also important to maintain the consistency of other input data sets used to produce this climate data record. In this paper, we address aspects that could potentially affect the CERES TOA flux data quality. Discontinuities in imager calibration can affect cloud retrieval which can lead to erroneous flux trends. When imposing an artificial 0.6 per decade decreasing trend to cloud optical depth, which is similar to the trend difference between CERES Edition 2 and Edition 4 cloud retrievals, the decadal SW flux trend changed from $-0.35 \pm 0.18 \mathrm{Wm}^{-2}$ to $0.61 \pm 0.18 \mathrm{Wm}^{-2}$. This indicates that a $13 \%$ change in cloud optical depth results in about $1 \%$ change in the SW flux. Furthermore, different CERES instruments provide valid fluxes at different viewing zenith angle ranges, and including fluxes derived at the most oblique angels unique to S-NPP $\left(>66^{\circ}\right)$ can lead to differences of $0.8 \mathrm{Wm}^{-2}$ and $0.3 \mathrm{Wm}^{-2}$ in global monthly mean instantaneous SW flux and LW flux. To ensure continuity, the viewing zenith angle ranges common to all CERES instruments $\left(<66^{\circ}\right)$ are used to produce the long-term Earth's radiation budget climate data record. The consistency of cloud properties retrieved from different imagers also needs to be maintained to ensure the TOA flux consistency.
\end{abstract}

Keywords: Earth's radiation budget; climate data record; cloud properties; angular distribution model

\section{Introduction}

Earth's radiation budget (ERB) at the top-of-atmosphere (TOA) is one of the most critical variables that shows the combined effects of many processes within the Earth-atmosphere system. Currently, the Clouds and the Earth's Radiant Energy System (CERES) instruments [1,2] have been providing continuous global TOA reflected shortwave (SW) radiation and outgoing longwave (LW) radiation (OLR) since 2000. Seven CERES instruments have flown on five different satellites thus far. Table 1 listed the CERES flight mode (FM) on different satellites, imagers that they fly alongside with, their orbit altitude, and their nominal nadir footprint size. 
Table 1. List of CERES instruments on different satellites.

\begin{tabular}{ccccc}
\hline Satellites & Flight Model & Imager & Altitude $(\mathbf{k m})$ & Nadir Footprint Size $\mathbf{( k m )}$ \\
\hline TRMM & pre-FM & VIRS & 350 & 10 \\
Terra & FM1, FM2 & MODIS & 705 & 20 \\
Aqua & FM3, FM4 & MODIS & 705 & 20 \\
Soumi-NPP & FM5 & VIIRS & 824 & 24 \\
NOAA-20 & FM6 & VIIRS & 824 & 24 \\
\hline
\end{tabular}

The CERES instrument consists of a three-channel broadband scanning radiometer [1]. The scanning radiometer measures radiances in shortwave (SW, 0.3-5 $\mu \mathrm{m})$ channel, total $(0.3-200 \mu \mathrm{m})$ channel, and window (WN, 8-12 $\mu \mathrm{m}$ ) channel for FM1-FM5 and longwave ( $\mathrm{LW}, 5-35 \mu \mathrm{m})$ channel for FM6. For FM1-FM5, LW radiance is derived as the difference between total and SW channels; for FM6, the LW channel measurement offers an independent check to the LW radiance derived by differencing total and SW channels. These measured radiances $(I)$ at a given sun-Earth-satellite geometry are converted to outgoing reflected solar and emitted thermal TOA radiative fluxes $(F)$ as:

$$
F\left(\theta_{0}\right)=\frac{\pi I\left(\theta_{0}, \theta, \phi\right)}{R_{j}\left(\theta_{0}, \theta, \phi\right)} .
$$

where $\theta_{0}$ is the solar zenith angle, $\theta$ is the CERES viewing zenith angle, $\phi$ is the relative azimuth angle between CERES and the solar plane, and $R_{j}\left(\theta_{0}, \theta, \phi\right)$ is the anisotropic factor for scene type $j$. Here, scene type is a combination of variables (e.g., surface type, cloud fraction, cloud optical depth, cloud phase, aerosol optical depth, precipitable water, lapse rate, etc.) that are used to group the data to develop distinct angular distribution models (ADMs). The scene type classifications are made possible by the imagers that are flying alongside the CERES instruments. Note the SW ADMs are developed as a function of $\theta_{0}, \theta, \phi$ for each scene type, whereas the LW ADMs are a weak function of $\theta_{0}$ and $\phi$ and are developed only as a function of $\theta[3,4]$.

To create a long-term climate data record of the ERB using CERES observations, consistency in instrument calibration and algorithm implementation must be maintained throughout the entire time series. Loeb et al. [2] detailed how the gains and spectral response functions are determined for CERES instruments to ensure radiance consistency over time and across different instruments. The CERES measured radiances are converted to fluxes using scene-type dependent anisotropic factors (Equation (1)). These anisotropic factors are determined using the CERES rotating azimuth plane data collected at the beginning of the Terra and Aqua missions and the cloud properties retrieved from MODIS spectral measurements. It is evident that any drift in CERES measured radiances will result in drift in fluxes, but how will drift in imager spectral radiances affect the flux inversion by changing the anisotropic factor selection is unknown. In this paper, we will quantify the impact of imager radiance drift on flux inversion. Furthermore, the maximum viewing zenith angle (VZA) of S-NPP CERES footprints with VIIRS cloud retrievals is about $71.4^{\circ}$, whereas it is only about $66^{\circ}$ for CERES on Terra and Aqua. The impact of the VZA ranges on cloud properties and fluxes is discussed in Section 4. As shown in Table 1, the imagers on Aqua and S-NPP are different, and VIIRS does not have any infrared channels sensitive to water vapor and carbon dioxide. Therefore the MODIS cloud retrieval algorithms need to be modified to apply to S-NPP observations. The impact on cloud property retrieved from MODIS and VIIRS is detailed in Section 5. Discussions and conclusions are presented in Section 6.

\section{CERES Data Production}

\subsection{CERES ADMs}

To facilitate the construction of ADMs, there are pairs of identical CERES instruments on both Terra and Aqua (see Table 1). At the beginning of these missions one of the instruments on each 
satellite was always placed in a rotating azimuth plane (RAP) scan mode, while the other one was placed in cross-track mode to provide spatial coverage. When in RAP mode, the instrument scans in elevation as it rotates in azimuth, thus acquiring radiance measurements from a wide range of viewing combinations. There are about 60 months of RAP data collected on Terra and about 32 months of RAP data collected on Aqua.

The spatial resolution of the CERES instruments on Terra and Aqua is about $20 \mathrm{~km}$ at nadir, and they are flying with MODIS instruments. The spatial resolution of CERES instruments on S-NPP and NOAA-20 is about $24 \mathrm{~km}$ at nadir, and they are flying with VIIRS instruments. The higher-resolution imagers provide cloud retrievals for every CERES field of view (FOV). The cloud algorithms developed by the CERES cloud working group retrieve cloud fraction $(f$, in $\%)$, cloud optical depth, cloud phase (liquid $=1$, and ice $=2$ ), cloud top and effective temperature/pressure (among other variables) based on imager pixel-level measurements [5-7]. These pixel-level cloud properties are spatially and temporally matched with the CERES FOV. If the cloud top pressure within a CERES FOV is significantly different, up to two non-overlapping cloud layers are defined [8]. For each cloud layer, pixel-level cloud properties are weighted by the CERES point spread function (PSF, [9]) to provide layer-mean cloud properties. Similarly, spectral radiances from MODIS/VIIRS observations are averaged over the CERES footprints weighted by the CERES PSF. Layer-mean cloud properties are then weighted by the layer cloud fractions to derive the cloud properties over the CERES FOV. These cloud properties are used for scene type classification. Cloud detection and cloud property retrievals are assessed through comparison with CALIPSO and CloudSat $[7,10]$. Instantaneous comparison of nadir daytime cloud detection agrees with CALIPSO in 90-99\% of the cases over snow-free areas, and in $89-94 \%$ of the cases over snow-covered areas. With a comparison using only single-phase CALIPSO pixels, the cloud top phase from MODIS retrievals agree with CALIPSO $95.8 \%$ and $92.0 \%$ of the time over snow-free and snow/ice-covered areas during the daytime. Comparisons of other cloud properties can be found in [10].

Besides cloud properties, surface types, and the snow and ice percentage cover are also used for scene type classification. The International Geosphere Biosphere Program ([11], IGBP) global land cover data set and a combination of the National Snow and Ice Data Center (NSIDC) microwave snow/ice map and the National Environmental Satellite, Data and Information Service (NESDIS) snow/ice map are utilized for this purpose. The spatial resolution of IGBP is $10 \mathrm{~min}$ and up to eight surface types are kept for each CERES FOV. The spatial resolutions for both snow/ice maps are also $10 \mathrm{~min}$. These two maps are complementary to each other. NESDIS uses imager data to identify snow and sea ice and provide snow and sea ice information near the coast, whereas NSIDC does not provide microwave retrievals within $50 \mathrm{~km}$ of the coast.

The Edition 4 CERES ADMs [4] are constructed for various scene types. Over a given scene type $(j)$, the CERES measured radiances are sorted into discrete angular bins. Averaged radiances $(\hat{I})$ in all angular bins are calculated and all radiances in the upwelling directions are integrated to provide the $\operatorname{ADM}$ flux $(\hat{F})$. The ADM anisotropic factors $(R)$ for scene type $j$ are then calculated as:

$$
R_{j}\left(\theta_{0}, \theta, \phi\right)=\frac{\pi \hat{I}\left(\theta_{0}, \theta, \phi\right)}{\int_{0}^{2 \pi} \int_{0}^{\frac{\pi}{2}} \hat{I}\left(\theta_{0}, \theta, \phi\right) \cos \theta \sin \theta d \theta d \phi}=\frac{\pi \hat{I}\left(\theta_{0}, \theta, \phi\right)}{\hat{F}\left(\theta_{0}\right)},
$$

Over cloudy ocean and land scenes, the SW ADMs were constructed using a sigmoidal function that relates CERES radiances and cloud properties retrieved from MODIS [4]. Under cloudy conditions, the magnitude of CERES radiance in a given angular bin is most sensitive to cloud fraction $(f$, in \%), cloud optical depth $(\tilde{\tau})$, and effective cloud phase (ECP), which is a PSF-weighted average of the cloud phase derived from imager pixel data ( 1 for liquid clouds, and 2 for ice clouds). The analytical fits were derived as a function of $\ln (f \tau)$ separately for liquid $(1.00<\mathrm{ECP}<1.01)$, mixed $(1.01 \leq \mathrm{ECP} \leq 1.75)$, and ice $(1.75<\mathrm{ECP} \leq 2.00)$ clouds. For each CERES radiance measurement $\left(I_{0}\right)$, the scene type is determined based on the cloud properties retrieved from the imager and other ancillary datasets to select the appropriate anisotropic factor to convert the radiance to flux using Equation (1). 


\subsection{CERES Energy Balanced and Filled (EBAF) Product}

CERES Level-3 data products provide monthly TOA flux at $1^{\circ}$ latitude by $1^{\circ}$ longitude spatial resolution, and it is the only global dataset that can be used to study the variations of ERB over a range of time-space scales. However, the absolute accuracy requirement necessary to quantify the Earth's energy imbalance (EEI) is much higher than any current instruments can deliver. The EEI ranges between 0.5 and $1 \mathrm{Wm}^{-2}$ [12]. This is a small residual of TOA flux of the order of $340 \mathrm{Wm}^{-2}$, about $0.15 \%$ of the total incoming and outgoing radiation at the TOA. Given the current uncertainty in instrument calibration and algorithm implementation, the net imbalance is about $4.3 \mathrm{Wm}^{-2}$ using the most recent CERES Edition 4 data product [13]. The CERES EBAF dataset uses an objective constrainment algorithm to adjust SW and LW TOA fluxes within their ranges of uncertainty to remove the inconsistency between average global net TOA flux and heat storage in the Earth-atmosphere system [13,14]. Additionally, because of the relatively coarse spatial resolution of the CERES instruments (20-km at nadir), the standard CERES Level-3 data products have many spatial gaps in monthly mean clear-sky TOA flux maps due to the absence of cloud-free areas occurring at the CERES footprint scale in some $1^{\circ} \times 1^{\circ}$ regions. In EBAF, this problem is mitigated by inferring clear-sky fluxes from both CERES and MODIS measurements to produce a new clear-sky TOA flux climatology for every $1^{\circ} \times 1^{\circ}$ grid cell every month.

\section{CERES TOA SW Flux Trend}

The CERES Ed4.0 EBAF data set represents the best effort in producing climate data record to achieve consistency throughout the entire time series for assessing climate variability (e.g., [15-17]), and for evaluating climate models (e.g., [18-20]). When the TOA reflected SW flux trend from EBAF Ed4.0 is compared with that from EBAF Ed2.8, we note that the decreasing trend in Ed4.0 is about four times larger than that from Ed2.8 (Figure 1). On the contrary, the trends of the TOA LW flux from these two editions are very similar. To understand if the SW flux trend difference is caused by the CERES instrument calibration difference between these two editions, we compared the TOA flux anomaly produced using the same cloud retrievals and ADMs (those used to produce Ed2.8 EBAF) but different calibration coefficients used in Ed2.8 and Ed4.0 EBAF. The resulting anomalies are nearly identical with the decadal trends agree within their $95 \%$ uncertainty range (not shown), indicating that the CERES calibration differences are not the cause for the differences seen in Figure 1.
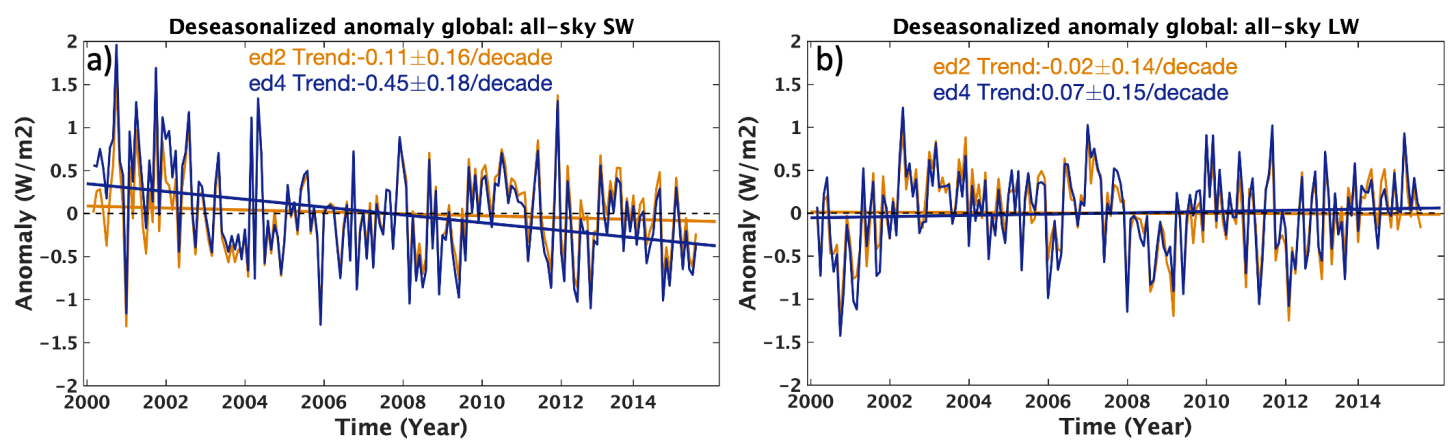

Figure 1. Anomaly in global monthly mean all-sky TOA reflected SW flux (a) and TOA LW flux (b). Orange lines are for Ed2.8 EBAF and navy lines are for Ed4.0 EBAF.

Figure 2 shows the global daytime monthly mean anomalies of cloud fraction and cloud optical depth using Edition 2 (Ed2) cloud retrievals (orange lines) and Edition 4 (Ed4) cloud retrievals (navy lines) from Terra MODIS. Cloud fraction anomalies show small differences between Ed2 and Ed4, but the cloud optical depth anomalies differ drastically. The Ed2 cloud optical depth shows a sharp decreasing trend with precipitous drops occurring in late 2003 and 2009. The sharp drop in cloud optical depth seen in late 2003 is related to the MODIS Terra solar diffuser door anomaly in May 
2003 which eventually led to a decision to keep the solar diffuser door open for the remainder of the mission. The diffuser door anomaly resulted in a much faster degradation rate of the MODIS visible channels [21]. The abrupt change in 2009 was caused by the solar diffuser degradation, which was about $1.5 \%$ for Terra-MODIS [22]. These degradations in the Terra MODIS visible channels were not corrected in Collection 4 and Collection 5 data that were used for CERES Ed 2 cloud retrievals, but have been corrected in Collection 6 . Therefore the Ed4 cloud retrievals are free from this artificial trend.

MODIS cloud optical depths are used to select anisotropic factors in converting CERES radiances to radiative fluxes, the different optical depth trends shown in Figure 2 may have contributed to the different SW TOA flux trends as well. To quantify how artificial cloud optical depth trend impacts the TOA SW flux trend, we impose an Ed2-like cloud optical depth trend to the Ed4 retrievals. The global mean cloud optical depth trends differ by 0.6 per decade between these two editions. To force the Ed4 cloud optical depth to have a trend similar to that of Ed2, cloud optical depths of all cloudy footprints in Ed 4 are decreased by 0.005 per month and are set to be 0.03 when negative cloud optical depths are encountered. The CERES TOA fluxes inverted by using ADMs selected based on Ed4 cloud properties are compared with the TOA fluxes inverted by using the same ADMs and cloud properties except that the cloud optical depths are imposed with an Ed2-like trend. All simulations are based on the CERES monthly mean Single Scanner Footprint TOA/Surface Fluxes and Cloud (SSF) data processing for daytime.
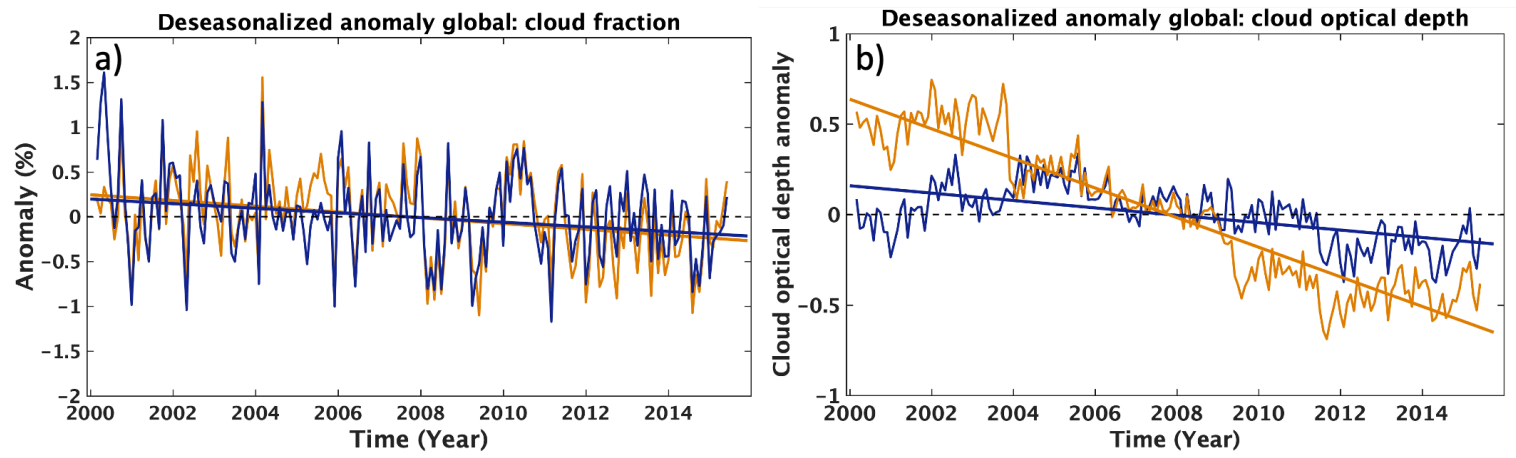

Figure 2. Anomaly in global monthly mean cloud fraction (a) and cloud optical depth (b). Oranges lines are from the CERES Edition 2 cloud product and navy lines are from CERES Edition 4 cloud product.

Figure 3 shows the TOA flux trend derived using the Ed4 clouds (navy), and by imposing a 0.005 per month decreasing trend to the Ed4 cloud optical depth (orange). The decreasing TOA SW flux trend of $-0.35 \pm 0.18 \mathrm{Wm}^{-2}$ per decade of the Ed4 data was reversed to an increasing trend of $0.61 \pm 0.18 \mathrm{Wm}^{-2}$ per decade. The reversal of the SW flux trend is solely caused by the imposed trend in cloud optical depth as all other inputs and algorithms are identical between them. Figure 4 shows the SW anisotropic factors for liquid clouds over ocean solar zenith angles of $30^{\circ}$ and $50^{\circ}$ for a typical side scattering angle that CERES collects measurements when in cross track mode. The CERES SW flux is determined by accounting the anisotropy of the radiance field, and the anisotropic factors are selected based upon the cloud properties. When cloud optical depths decrease (while the cloud fraction stays more or less the same), the anisotropic factors also decrease for observations taken at most viewing zenith angles less than $\sim 55^{\circ}$ but increase for more oblique views. The decreasing cloud optical depth thus causes an overall increase in TOA SW flux, as the number of footprints with viewing zenith angles less than $\sim 55^{\circ}$ far outweigh those with viewing zenith angles greater than $\sim 55^{\circ}$. This simulation shows that the TOA SW flux trend in EBAF Ed2.8 was indeed 'flattened' by the trend in cloud optical depth caused by the MODIS calibration issues. Note the trend difference shown in Figure 3a is greater than the trend difference between EBAF 2.8 and EBAF 4.0 (Figure 1a). The possible explanations for the larger TOA SW flux trend change in the imposed cloud optical depth trend simulation are: (1) the imposed trend is continuous, whereas the Ed2 cloud optical depth shows 
step changes; (2) the impact of the MODIS calibration changes on cloud optical depth is different for optically thin and thick clouds; (3) ADMs are more sensitive to optical depth changes for optically thin than thick clouds.
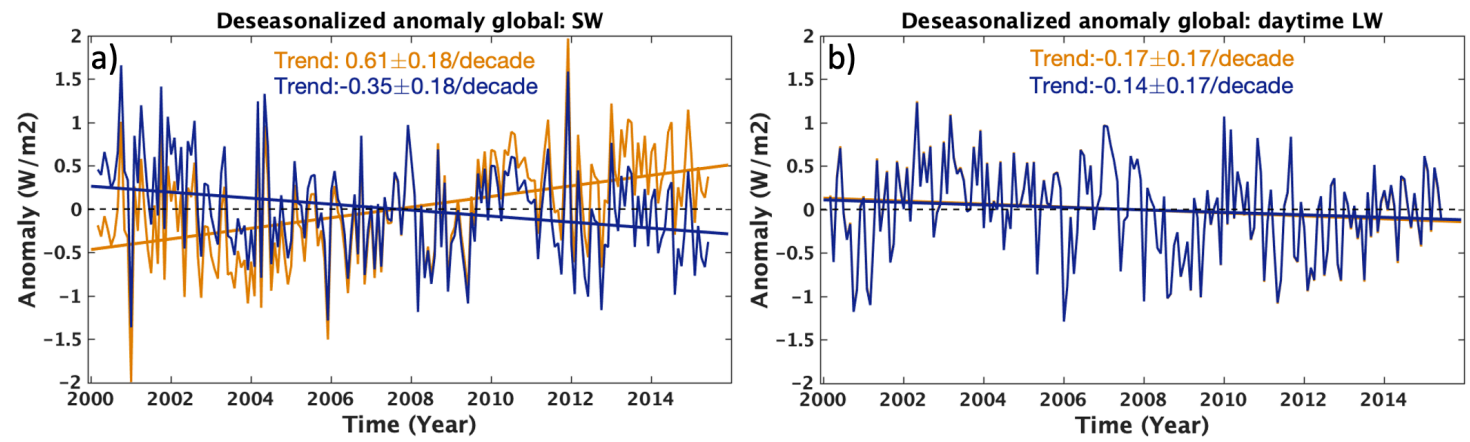

Figure 3. Anomaly in global monthly mean TOA SW fluxes (a) and TOA daytime LW fluxes (b) using cloud optical depth from Ed4 retrieval (navy lines) and imposing a 0.005 per month trend in Ed4 cloud optical depth for all cloudy footprints of Ed4 (orange lines).
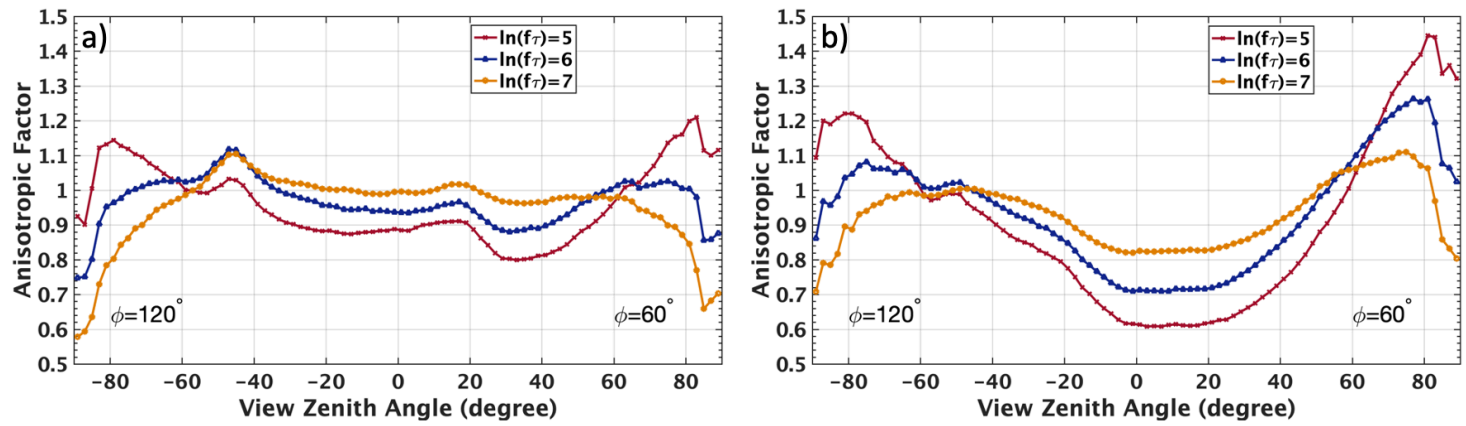

Figure 4. SW anisotropic factors for solar zenith angles of $30^{\circ}(\mathbf{a})$ and $50^{\circ}$ (b) for three $\ln (f \tau)$ values for liquid clouds over ocean at relative azimuth angle of $60^{\circ}$ and $120^{\circ}$. Here $f$ is the cloud fraction in \%, and $\tau$ is the cloud optical depth.

For the TOA LW flux, imposing a 0.005 per month decreasing trend to the Ed4 cloud optical depth has little impact on the trend. This is because the LW ADMs for cloudy conditions are constructed as a function of "pseudoradiance", which characterizes scenes in terms of cloud fraction, precipitable water, surface skin temperature, surface-cloud temperature difference, surface infrared emissivity, and cloud infrared emissivity [4]. The pseudoradiance has a weak dependence on visible cloud optical depth via cloud infrared emissivity and thus the imposed trend on cloud optical depth has little effect on the inverted LW flux.

This result demonstrates that to produce the ERB climate data record, not only it is paramount to maintain the CERES calibration stability, it is also important to maintain the imager calibration stability. Spurious changes in imager radiances can impact the retrieved cloud properties and thus lead to an erroneous TOA SW flux trend.

\section{Viewing Zenith Angle Impact on Imager Retrieved Cloud Property and CERES TOA Flux}

Since the MODIS imager can only scan to a maximum viewing zenith angle (VZA) of $\sim 66^{\circ}$, this means that only CERES footprints with VZA $<66^{\circ}$ are retained in the SSF data when CERES is in the cross track scan mode. The VIIRS imager on S-NPP and NOAA-20, however, scans to a maximum VZA of $\sim 71^{\circ}$ and the accompanying CERES instruments thus provide fluxes for all footprints with VZA $<72^{\circ}$. Cloud amount from satellite retrievals increases with the imager viewing zenith angle, and the increment is not uniform across different cloud regimes, with a more pronounced increase 
observed for broken cloud fields [23]. As demonstrated in Section 3, changes in cloud properties can affect the scene identification used to select the ADMs and thus affect the inverted fluxes.

Figure 5 shows the multi-year (2014-2018) mean cloud fraction from S-NPP VIIRS and the cloud fraction difference between all footprints and footprints with VZA $<66^{\circ}$. The differences are positive everywhere and the global mean cloud fractions derived using all footprints is about $0.5 \%$ greater than only using footprints with VZA $<66^{\circ}$. Note the sharp line around $65^{\circ} \mathrm{N}$ is because north of this latitude the number of observations taken at VZA $>66^{\circ}$ is very low. The largest differences (up to $2 \%$ ) are observed over tropical oceans and Antarctica where multi-year mean cloud fractions are around $50 \%$. Regions where cloud fractions exceed $80 \%$ and desert areas with very low cloud amount show smaller differences. The VZA dependency is also smaller off the west coast of Africa, where a special cloud mask is implemented over this dust laden region [7], than adjacent regions. Many studies [23-25] have noted that satellite retrieved cloud fraction increases as the VZA increases and attributed this to viewing perspective of the sensor, increase in path length, and in pixel size. Although the increase of cloud fraction at the very oblique angles $\left(>66^{\circ}\right)$ is obvious, the magnitude is relatively small when compared to the cloud fraction difference between near-nadir $\left(\mathrm{VZA}<10^{\circ}\right.$ ) views and oblique views $\left(\mathrm{VZA}>60^{\circ}\right)$. Global mean cloud fraction retrieved from near-nadir view footprints is about $8 \%$ less than using oblique view footprints (not shown).
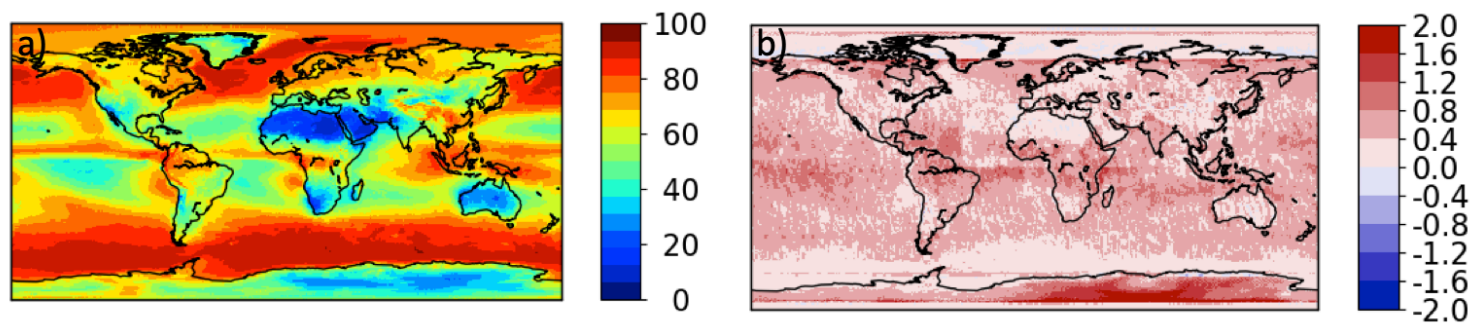

Figure 5. Multi-year (2014-2018) mean daytime cloud fraction from S-NPP VIIRS retrieval (a), and cloud fraction difference between retrievals using all footprints and only using footprints with $\mathrm{VZA}<66^{\circ}(\mathbf{b})$.

The dependency of cloud fraction on VZA also propagates into other cloud properties. Figure 6 shows the multi-year mean daytime liquid and ice cloud optical depth from S-NPP VIIRS retrievals and the difference between all footprints and footprints with VZA $<66^{\circ}$. For liquid clouds, optical depth differences are mostly negative with the largest differences seen over northern high latitude land regions. Positive differences are observed over desert and high elevation regions, and over the Southern Ocean and Arctic Ocean. For ice clouds, the difference shows a large land and sea contrast. Negative differences of up to 0.4 are observed over the land regions, whereas mostly positive differences are observed over ocean except negative differences over high latitude oceanic regions. Many factors contribute to the VZA dependency of cloud optical depth retrievals. The dependency is more pronounced under oblique solar zenith angles. Studies also show that in the backward scattering directions cloud optical depth decreases with VZA whereas it increases with VZA in the forward scattering directions, and that the cloud optical depth dependency on VZA tends to be larger in the backward scattering directions than in the forward scattering directions (e.g., [26-28]). Thus the overall biases depend on the sampling differences in the forward and backward directions. The biases also depend on the cloud types and cloud spatial distribution pattern such that the broken clouds are more susceptible to these VZA dependency biases than uniformly-distributed clouds.

Given that cloud properties depend on VZA and that CERES empirical ADMs are functions of these cloud properties, different ranges of VZAs on different CERES instruments can affect the continuity of the ERB climate data record. Figure 7 shows the monthly mean instantaneous daytime SW flux difference averaged using all footprints and using footprints with VZA $<66^{\circ}$ only from CERES S-NPP observations in 2014. For all four months, the global monthly mean daytime SW flux would be about 0.7 to $0.9 \mathrm{Wm}^{-2}$ smaller if the VZA range is not restricted. Regionally, the flux can differ by up to $10 \mathrm{Wm}^{-2}$. Large differences are observed around the ITCZ and around $60^{\circ} \mathrm{N}$ and 
$60^{\circ}$ S. Figures 8 and 9 show the daytime and nighttime monthly mean LW flux differences averaged using all footprints and also using footprints with VZA $<66^{\circ}$ only from CERES S-NPP observation. For daytime, the LW flux would be about $0.1-0.3 \mathrm{Wm}^{-2}$ smaller if all VZAs are included, and the nighttime LW flux would be about $0.1 \mathrm{Wm}^{-2}$ smaller. Regionally, the LW flux differences of up to $4 \mathrm{Wm}^{-2}$ are seen over the tropical oceans. Similar to SW flux, large differences are observed near the ITCZ and over the western Pacific Ocean. However, it is problematic to isolate the contributing factors that cause the flux differences as they depend on cloud type, cloud amount, cloud optical depth, and phase, as well as the relative number of observations taken with VZA $>66$ degrees and $\leq 66$ degrees.

To ensure continuity of the CERES flux data record on the global and regional scales, we decided to only include footprints with VZA $<66^{\circ}$ for CERES S-NPP and NOAA-20 Level 3 and Level 4 product to ensure continuity of ERB climate data record. However, footprints with VZA $>66^{\circ}$ are kept in the Level 2 product for completeness and for process studies.
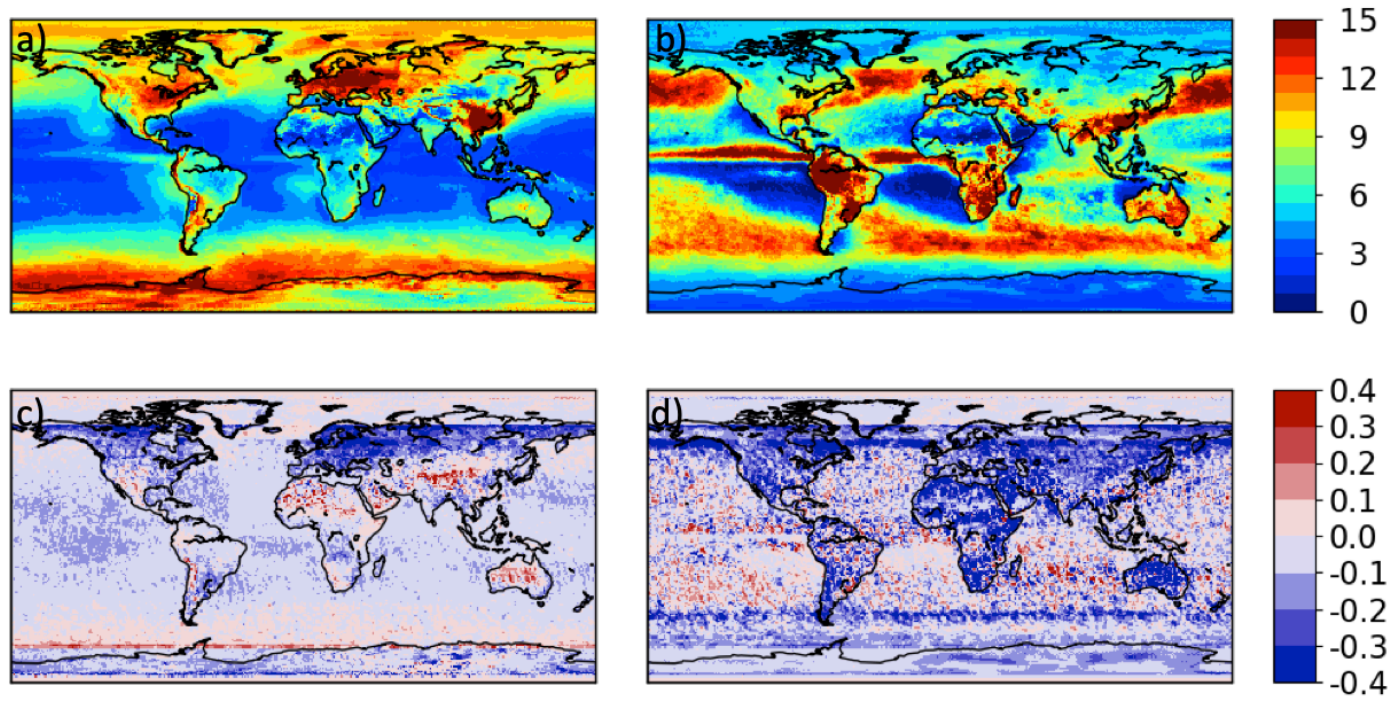

Figure 6. Multi-year (2014-2018) mean daytime liquid cloud optical depth (a) and ice cloud optical depth (b) from S-NPP VIIRS retrieval, and the cloud optical depth difference between retrievals using all footprints and only using footprints with VZA $<66^{\circ}$ for liquid cloud (c) and ice cloud (d).
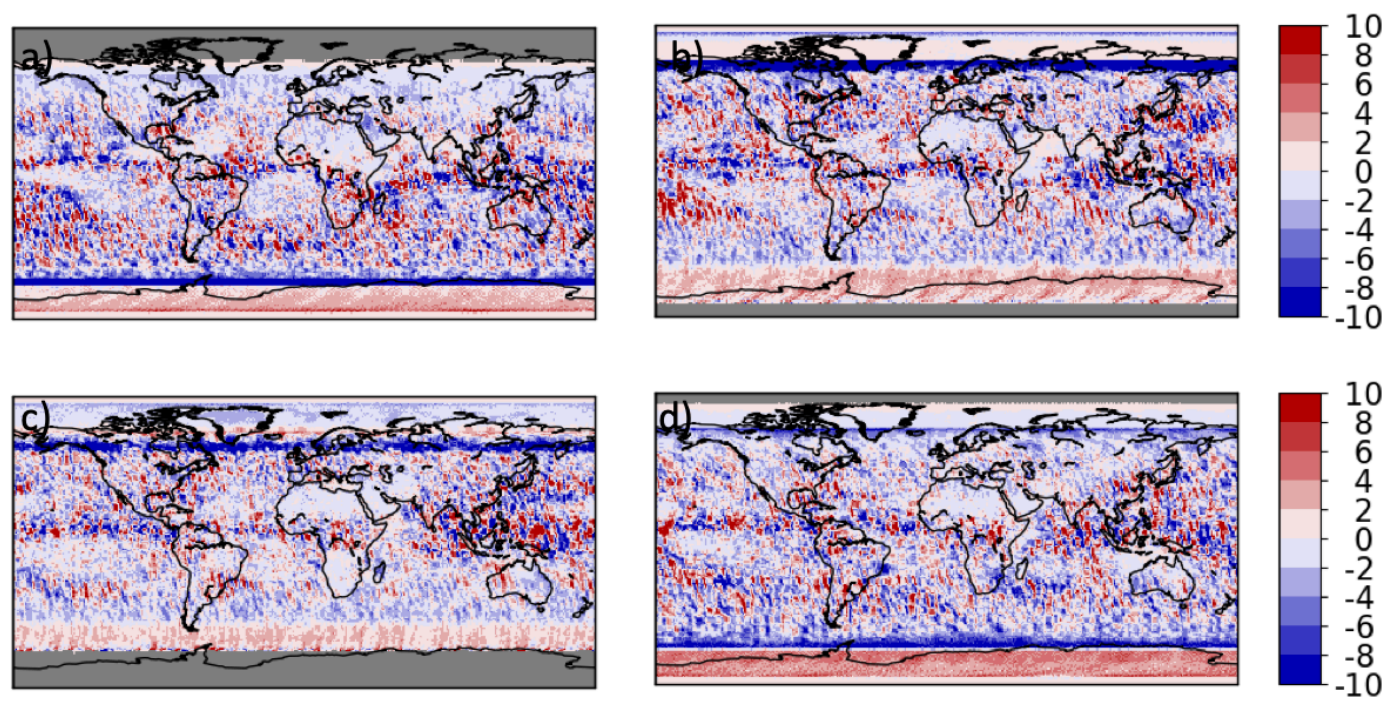

Figure 7. Monthly mean instantaneous daytime SW flux difference between using all footprints and only using footprints with viewing zenith angles less than $66^{\circ}$ for January (a), April (b), July (c), and October (d) 2014 from CERES NPP observation. Regions in grey only have nighttime observations. 

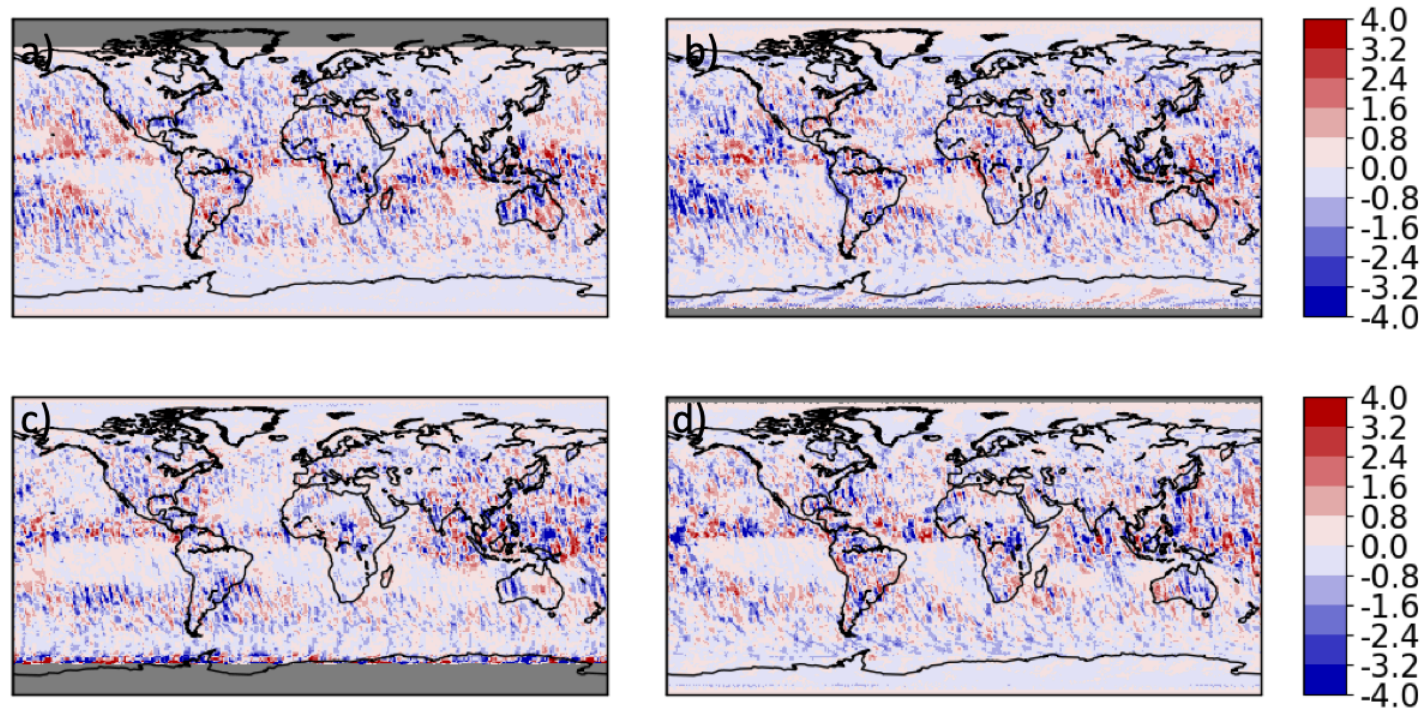

Figure 8. Monthly mean daytime LW flux difference between using all footprints and only using footprints with viewing zenith angles less than $66^{\circ}$ for January (a), April (b), July (c), and October (d) 2014 from CERES NPP observation. Regions in grey only have nighttime observations.
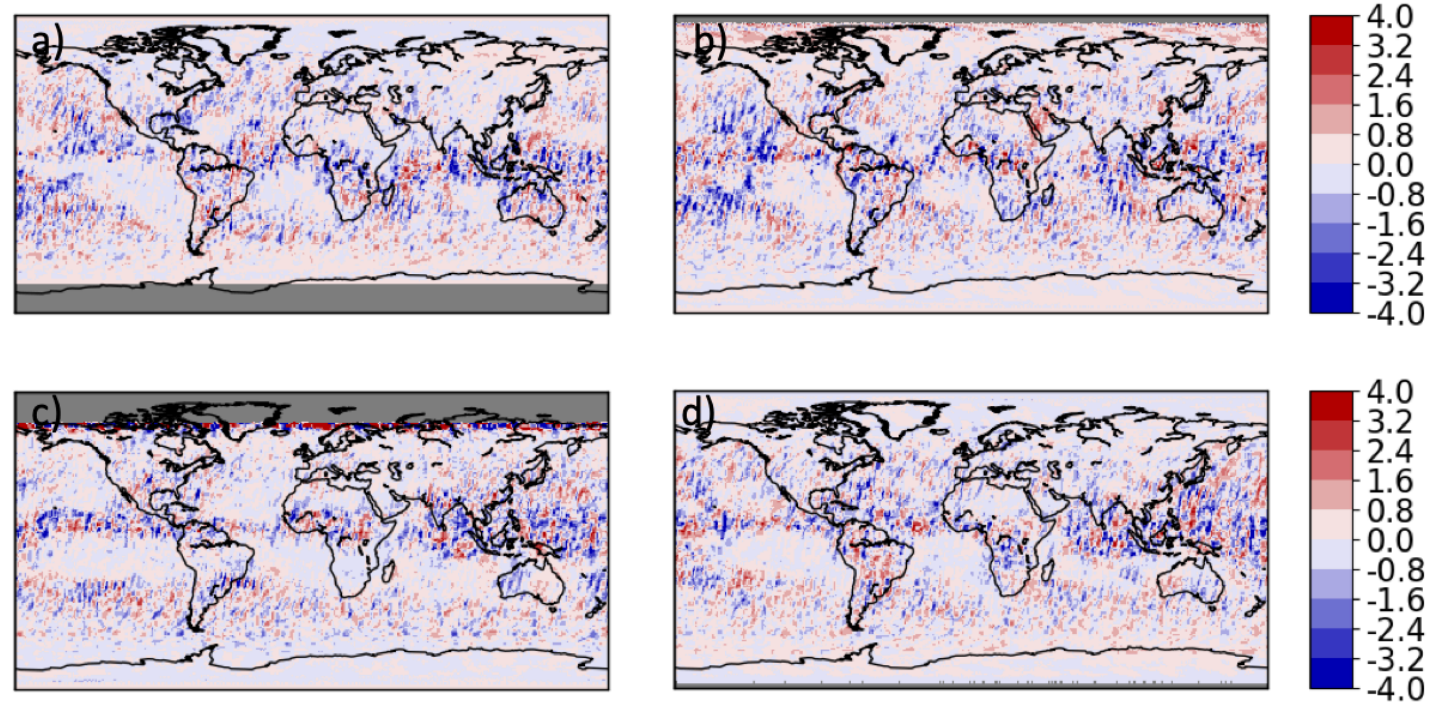

Figure 9. Monthly mean nighttime LW flux difference between using all footprints and only using footprints with viewing zenith angles less than $66^{\circ}$ for January (a), April (b), July (c), and October (d) 2014 from CERES NPP observation. Regions in grey only have daytime observations.

\section{Cloud Property Consistency between MODIS and VIIRS}

Both Aqua and S-NPP are in sun-synchronous orbits, but fly at different altitudes (see Table 1). The S-NPP flies directly over Aqua in about every $64 \mathrm{~h}$. The overlap provides a great opportunity to exam the consistency of cloud property retrieved from MODIS and VIIRS. These two imagers have many similar channels, but the most striking difference is the lack of water vapor $($ at $6.7 \mu \mathrm{m})$ and carbon dioxide $(15 \mu \mathrm{m})$ channels on VIIRS. The lack of these channels makes the application of MODIS-based cloud retrieval algorithm to VIIRS problematic, and algorithm changes have to be made to accommodate these differences. Here we use matched footprints on Aqua and S-NPP to assess the cloud fraction and cloud optical depth difference.

The matching criteria used are that both the latitude and longitude differences are less than $0.05^{\circ}$, the solar zenith angle and viewing zenith angle differences are less than $2^{\circ}$, and the relative azimuth 
angle difference is less than $5^{\circ}$. To minimize the impact of footprint size difference on the comparison, we only use footprints with viewing zenith angles less than $10^{\circ}$. The cloud retrieval algorithms are different for polar and non-polar regions, therefore the comparisons are done separately for polar and non-polar regions and only daytime comparisons are presented here. We used Aqua Edition 4 and NPP Edition 1 datasets for this comparison.

Figure 10 shows the probability distribution of the cloud fraction and cloud optical depth differences between S-NPP and Aqua separately for regions between $60^{\circ} \mathrm{S}-60^{\circ} \mathrm{N}$ and for regions poleward of $60^{\circ}$. The number of matched footprints over the non-polar regions is 32,222, and most of them are over ocean; whereas the number of matched footprints over polar regions is only 5880 . As expected, the polar regions have more and thicker clouds than the non-polar regions. The cloud fraction from S-NPP on average is smaller than that from Aqua by about 1\%, with the root mean square (RMS) error around 7\% for both the non-polar and polar regions. The cloud optical depth from S-NPP and Aqua agree fairly well with each other over non-polar regions, with the bias close to 0 and the RMS error of 2.3. However, the optical depth difference over polar regions is much larger. The cloud optical depth from S-NPP is about 0.4 greater than that from Aqua on average and the RMS error is over 9.

As mentioned early, the CERES ADMs are functions of cloud fraction and cloud optical depth. It is important to maintain cloud property consistency in order to achieve flux consistency. Algorithm development is underway to reconcile the cloud property differences.
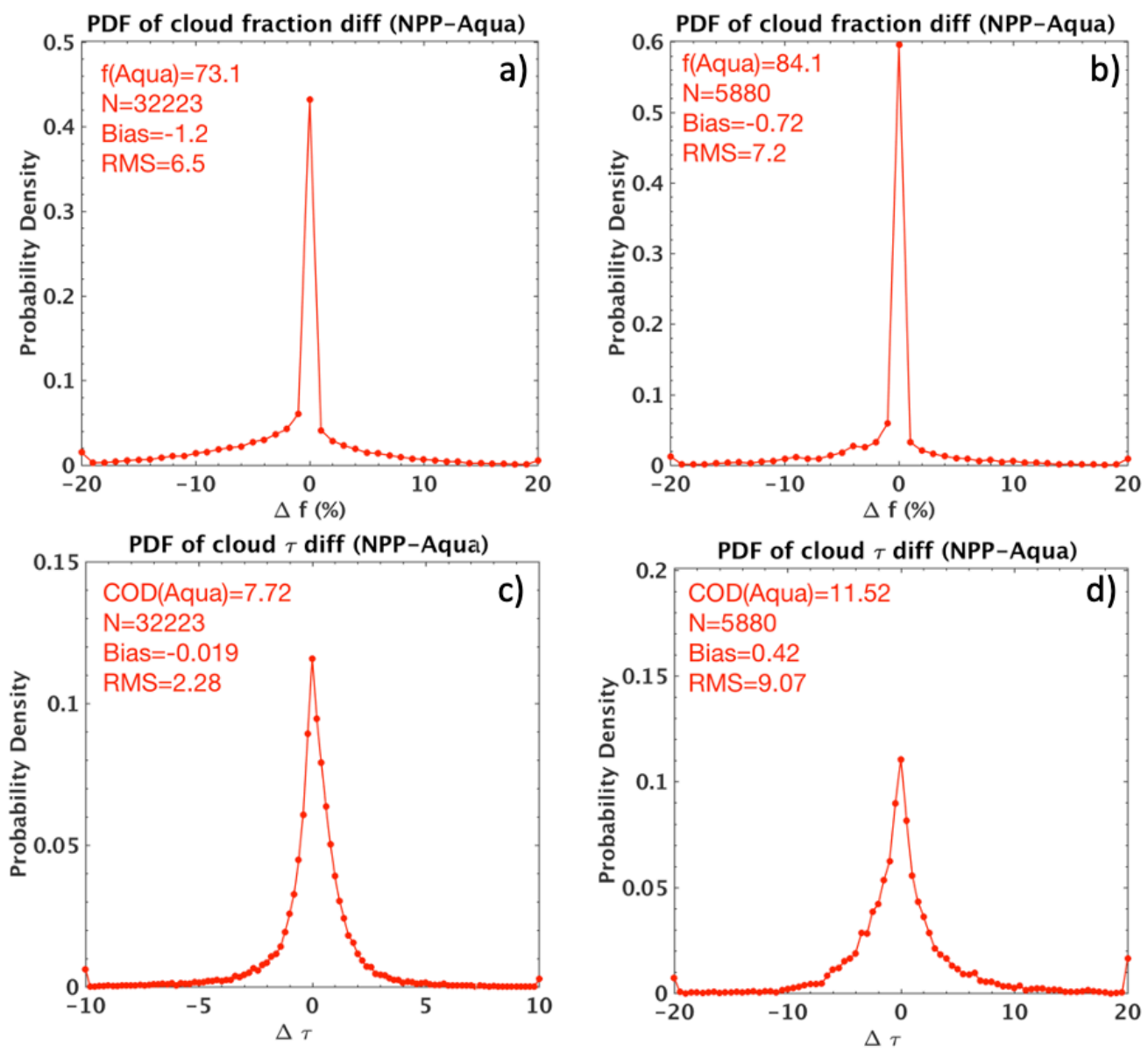

Figure 10. Probability distribution function for the cloud fraction $(f$, in $\%)$ differences between S-NPP and Aqua for regions between $60^{\circ} \mathrm{S}-60^{\circ} \mathrm{N}(\mathrm{a})$ and for regions poleward of $60^{\circ}(\mathrm{b})$, and the cloud optical depth $(\tau)$ differences for regions between $60^{\circ} \mathrm{S}-60^{\circ} \mathrm{N}(\mathrm{c})$ and for regions poleward of $60^{\circ}(\mathrm{d})$. 


\section{Discussion and Conclusions}

Producing a multi-decade-long data record that is suitable for detecting and quantifying the climate variability and changes is a very challenging task. Climate data records that are decades long generally involve multiple satellites and consistency of the measurements across multiple platforms is key to maintain the stability of the measurements. Additionally, for data records that use other input data sets, it is also important to maintain the consistency of the input data sets.

CERES TOA flux data set is produced by using the radiances measured by the CERES instruments, which are then converted to fluxes by using the scene-type dependent ADMs. These ADMs are functions of cloud properties that are retrieved from imagers that are flying alongside the CERES instruments. In this paper, we illustrated that a spurious discontinuity in imager calibration introduced an erroneous trend in cloud optical depth retrieval and thus affected the TOA SW flux trend. When the Ed 4 cloud optical depth was decreased by 0.005 per month to mimic the Ed 2 cloud optical depth trend, the resulting TOA SW flux trend changed from $-0.35 \pm 0.18 \mathrm{Wm}^{-2}$ per decade to $0.61 \pm 0.18 \mathrm{Wm}^{-2}$ per decade, with all other inputs and algorithms being identical. The global daytime mean cloud optical depth is approximately 4.5 , thus 0.6 per decade trend represents a $13 \%$ change of the global mean value. The global mean SW flux is on the order of $100 \mathrm{Wm}^{-2}$, thus $0.96 \mathrm{Wm}^{-2}$ per decade trend change represents a $1 \%$ change of the global mean value. This means that a $13 \%$ change in cloud optical depth results in about $1 \%$ change in the SW flux.

CERES instruments on different satellites provide valid fluxes at different viewing zenith angle ranges. CERES instruments on Terra and Aqua only provide fluxes for VZA less than $66^{\circ}$ whereas CERES instruments on S-NPP and NOAA-20 provide fluxes for VZA less than $72^{\circ}$. Satellite retrieved cloud fraction generally increases as the VZA increases because of viewing perspective of the sensor, increase in path length, and in pixel size. Global mean cloud fractions retrieved only using near-nadir view footprints can be $8 \%$ less than the cloud fraction retrieved only using oblique-view footprints. The global mean cloud fraction difference is $0.5 \%$ with and without the footprints with VZA $>66^{\circ}$. This VZA dependency also propagates to other cloud properties, and the retrieved cloud optical depth generally decreases as VZA increases. However, there are regional exceptions and the dependency of liquid cloud optical depth on VZA differs from that of ice clouds.

Different range of VZAs on different CERES instruments can affect the continuity of the ERB climate data record, as the cloud properties depend on VZA and that CERES empirical ADMs are functions of these cloud properties. The global monthly mean instantaneous SW flux difference averaged using all footprints and using only footprints with VZA $<66^{\circ}$ from CERES S-NPP observations are about 0.7 to $0.9 \mathrm{Wm}^{-2}$. Regionally, the flux can differ by up to $10 \mathrm{Wm}^{-2}$ with large differences around ITCZ and near $60^{\circ} \mathrm{N}$ and $60^{\circ} \mathrm{S}$. LW flux differences due to different VZA ranges are smaller comparing with the SW flux difference, with daytime and nighttime monthly mean LW flux difference less than $0.3 \mathrm{Wm}^{-2}$. Regionally, the $\mathrm{LW}$ flux differences up to $4 \mathrm{Wm}^{-2}$ are seen over the tropical oceans near the ITCZ and over the western Pacific Ocean. These flux differences caused by using different VZA ranges can result in a discontinuity in CERES TOA flux. To ensure continuity, the viewing zenith angle ranges common to all CERES instruments are used to produce the long-term Earth's radiation budget climate data record.

Using collocated CERES footprints on S-NPP and Aqua, cloud fraction and cloud optical depth retrieved from MODIS and VIIRS are compared against each other. The cloud fractions from these two imagers agree reasonable well for both polar and non-polar regions, with the bias around $1 \%$ and the RMS errors around 7\%. The cloud optical depths show good agreement over the non-polar regions, but VIIRS produces higher cloud optical depth than MODIS over the polar regions. Algorithm development is underway to minimize the cloud property differences between MODIS and VIIRS, which includes developing algorithm that uses channels that are common to both MODIS and VIIRS and placing them on the same radiometric scale.

Creating CERES TOA flux climate data records needs to ensure consistency not only in the radiance measurements across all CERES instruments over the last two decades and beyond, but also 
in the input data sets used. Producing CERES TOA flux represents the highest degree of data fusion of CERES, MODIS, VIIRS, and many operational geostationary satellites, together with input data sets of snow/ice map, aerosol assimilation model, and meteorological fields from GEOS assimilation system. To ensure the highest fidelity of the TOA SW flux for detecting and quantifying climate variability, consistency in satellite measurements as well as in input data used must be maintained.

Author Contributions: W.S., L.L., H.W. and Z.A.E. analyzed the data; W.S. wrote the manuscript; All authors provided edits to the manuscript. All authors have read and agreed to the published version of the manuscript.

Funding: This research received no external funding.

Acknowledgments: This research has been supported by the NASA CERES project. The CERES datasets were obtained from http:/ / ceres.larc.nasa.gov/order_data.php.

Conflicts of Interest: The authors declare no conflict of interest.

\section{References}

1. Wielicki, B.A.; Barkstrom, B.R.; Harrison, E.F.; Lee, R.B.; Smith, G.L.; Cooper, J.E. Clouds and the Earth's Radiant Energy System (CERES): An Earth Observing System Experiment. Bull. Am. Meteorol. Soc. 1996, 77, 853-868. [CrossRef]

2. Loeb, N.G.; Manalo-Smith, N.; Su, W.; Shankar, M.; Thomas, S. CERES top-of-atmosphere Earth radiation budget climate data record: Accounting for in-orbit changes in instrument calibration. Remote Sens. 2016, 8, 182. [CrossRef]

3. Loeb, N.G.; Kato, S.; Loukachine, K.; Manalo-Smith, N. Angular Distribution Models for Top-of-Atmosphere Radiative Flux Estimation from the Clouds and the Earth's Radiant Energy System Instrument on the Terra Satellite. Part I: Methodology. J. Atmos. Ocean. Technol. 2005, 22, 338-351. [CrossRef]

4. Su, W.; Corbett, J.; Eitzen, Z.A.; Liang, L. Next-Generation Angular Distribution Models for Top-of-Atmosphere Radiative Flux Calculation from the CERES Instruments: Methodology. Atmos. Meas. Tech. 2015, 8, 611-632. [CrossRef]

5. Minnis, P.; Sun-Mack, S.; Chen, Y.; Chang, F.L.; Yost, C.R.; Smith, W.L., Jr.; Heck, P.W.; Arduini, R.F.; Bedka, S.T.; Yi, Y.; et al. CERES MODIS cloud product retrievals for Edition 4, Part I: Algorithm changes. Geosci. Remote Sens. 2020, submitted.

6. Minnis, P.; Sun-Mack, S.; Young, D.F.; Heck, P.W.; Garber, D.P.; Chen, Y.; Spangenberg, D.A.; Arduini, R.F.; Trepte, Q.Z.; Smith, W.L.; et al. CERES Edition-2 cloud property retrievals using TRMM VIRS and TERRA and AQUA MODIS data, Part I: Algorithms. IEEE Trans. Geosci. Remote Sens. 2011, 49, 4374-4400. [CrossRef]

7. Trepte, Q.Z.; Minnis, P.; Sun-Mack, S.; Yost, C.B.; Chen, Y.; Jin, Z.; Hong, G.; Chang, F.L.; Smith, W.L., Jr.; Bedka, K.M.; et al. Global cloud detection for CERES Edition 4 using Terra and Aqua MODIS data. IEEE Trans. Geosci. Remote Sens. 2019, 57, 9410-9449. [CrossRef]

8. Loeb, N.G.; Manalo-Smith, N.; Kato, S.; Miller, W.F.; Gupta, S.K.; Minnis, P.; Wielicki, B.A. Angular Distribution Models for Top-of-Atmosphere Radiative Flux Estimation from the Clouds and the Earth's Radiant Energy System Instrument on the Tropical Rainfall Measuring Mission Satellite. Part I: Methodology. J. Appl. Meteorol. 2003, 42, 240-265. [CrossRef]

9. Smith, G.L. Effects of time response on the point spread function of a scanning radiometer. Appl. Opt. 1994, 33, 7031-7037. [CrossRef] [PubMed]

10. Yost, C.R.; Minnis, P.; Sun-Mack, S.; Chen, Y.; Smith, W.L., Jr. CERES MODIS Cloud Product Retrievals for Edition 4, Part II: Comparisons to CloudSat and CALIPSO. IEEE Trans. Geosci. Remote Sens. 2020, Submitted.

11. Loveland, T.R.; Belward, A.S. The International Geosphere Biosphere Programme data and information system global land cover dataset (DISCover). Acta Astronaut. 1997, 41, 681-689. [CrossRef]

12. von Schuckmann, K.; Palmer, M.D.; Trenberth, K.E.; Cazenave, A.; Chambers, D.; Champollion, N.; Hansen, J.; Josey, S.A.; Loeb, N.; Mathieu, P.P.; et al. An imperative to monitor Earth's energy imbalance. Nat. Clim. Chang. 2016, 6, 138-144. [CrossRef]

13. Loeb, N.G.; Doelling, D.R.; Wang, H.; Su, W.; Nguyen, C.; Corbett, J.; Liang, L.; Mitrescu, C.; Rose, F.G.; Kato, S. Clouds and the Earth's Radiant Energy System (CERES) Energy Balanced and Filled (EBAF) Top-of-Atmosphere (TOA) Edition-4.0 Data Product. J. Clim. 2018, 31, 895-918. [CrossRef] 
14. Loeb, N.G.; Wielicki, B.A.; Doelling, D.R.; Smith, G.L.; Keyes, D.F.; Kato, S.; Manalo-Smith, N.; Wong, T. Towards optimal closure of the Earth's top-of-atmosphere radiation budget. J. Clim. 2009, 22, 748-766. [CrossRef]

15. Forster, P.M. Inference of climate sensitivity from analysis of Earth's energy budget. Annu. Rev. Earth Planet Sci. 2016, 44, 85-106. [CrossRef]

16. Loeb, N.G.; Su, W.; Kato, S. Understanding climate feedbacks and sensitivity using observations of Earth's energy budget. Curr. Clim. Chang. Rep. 2016, 2, 170-178. [CrossRef] [PubMed]

17. Dessler, A.E.; Forster, P.M. An estimate of equilibrium climate sensitivity form interannual variability. J. Geophys. Res. 2018, 123, 8634-8645. [CrossRef]

18. Pincus, R.; Batstone, C.P.; Hofmann, R.J.P.; Taylor, K.E.; Glecker, P.J. Evaluating the present-day simulation of clouds, precipitation, and radiation in climate models. J. Geophys. Res. 2008, 113, D14209. [CrossRef]

19. Wang, H.; Su, W. Evaluating and understanding top of the atmosphere cloud radiative effects in Intergovernmental Panel on Climate Change (IPCC) fifth assessment report (AR5) cloupled model intercomparison project phase 5 (CMIP5) models using satellite observations. J. Geophys. Res. 2013, 118, 1-17. [CrossRef]

20. Wild, M.; Folini, D.; Schar, C.; Loeb, N.G.; Dutton, E.G.; Konig-Langlo, G. The global energy balance from a surface perspective. Clim. Dyn. 2013, 40,3107-3134. [CrossRef]

21. Erives, H.; Xiong, X.; Sun, J.; Esposito, J.; Xiong, S.; Barnes, W. Terra MODIS RSB on-orbit calibration and performance: Four years of data. In Sensors, Systems, and Next-Generation Satellites; Roland, M., Steven, P., Neeck, H.S., Eds.; SPIE: Bellingham, WA, USA, 2004; Volume 5570, pp. 342-351. [CrossRef]

22. Wu, A.; Xiong, X.; Doelling, D.R.; Morstad, D.; Angal, A.; Bhatt, R. Characterization of Terra and Aqua MODIS VIS, NIR, and SWIR Spectral Bands' Calibration Stability. IEEE Trans. Geosci. Remote Sens. 2013, 51, 4330-4338. [CrossRef]

23. Maddux, B.C.; Ackerman, S.A.; Platnick, S. Viewing geometry dependencies in MODIS cloud products. J. Atmos. Ocean. Technol. 2010, 27, 1519-1528. [CrossRef]

24. Minnis, P. Viewing zenith angle dependence of cloudiness determined from coincident GOES East and GOES West data. J. Geophys. Res. 1989, 94, 2303-2320. [CrossRef]

25. Zhao, G.; Di Girolamo, L. A cloud fraction versus view angle technique for automatic in-scene evaluation of the MISR cloud mask. J. Appl. Meteor. 2004, 43, 860-869. [CrossRef]

26. Loeb, N.G.; Varnai, T.; Winker, D.M. Influence of subpixel- scale cloud-top structure on reflectances from overcast stratiform cloud layers. J. Atmos. Sci. 1998, 55, 2960-2973. [CrossRef]

27. Varnai, T.; Marshak, A. View angle dependence of cloud optical thicknesses retrieved by Moderate Resolution Imaging Spectroradiometer (MODIS). J. Geophys. Res. 2007, 112. [CrossRef]

28. Liang, L.; Di Girolamo, L. A global analysis on the view-angle dependence of plane-parallel oceanic liquid water cloud optical thickness using data synergy from MISR and MODIS. J. Geophys. Res. 2013, 118, 2389-2403. [CrossRef]

(C) 2020 by the authors. Licensee MDPI, Basel, Switzerland. This article is an open access article distributed under the terms and conditions of the Creative Commons Attribution (CC BY) license (http:/ / creativecommons.org/licenses/by/4.0/). 